\title{
As dificuldades de uma tradução: um ensaio sobre o Sunzi bingfa 孫子兵法 e o contexto cultural brasileiro
}

André Bueno

Resumo: Em 2009, fui convidado a realizar a tradução do Sunzi bingfa (A Lei da Guerra de Sunzi) diretamente para o português. Embora o livro contasse com diversas versões feitas em nosso idioma, foi com espanto que constatei que não havia, aparentemente, nenhuma tradução direta desse afamado texto no Brasil. A trajetória da tradução do Sunzi Bingfa revelou uma série de questões fundamentais sobre a recepção da cultura chinesa no contexto brasileiro, que atravessam os mais diversos estereótipos, preconceitos, e a necessidade de redimensionar o próprio pensamento brasileiro sobre a questão do outro. Nesse texto, faremos um relato sobre a experiência de traduðir esse livro, sua recepção junto ao público, $e$ o desafio que ele expõe, acerca da sociedade brasileira, em face de seu profundo desconbecimento a respeito do mundo asiático.

Palavras-chave: Sunżi; Clássicos Chineses; Diálogo Intercultural.

O interesse pela cultura chinesa, no Brasil, é bastante recente. Desde a década de 1990, se ouviam notícias - sempre distantes - do crescimento econômico da China, mas nenhuma intenção real de investigá-la se desenvolvia. Iniciativas acadêmicas isoladas existiam, mas nenhuma com grande repercussão. Esse interesse se mantinha restrito a pontos focalizados da cultura chinesa: artes marciais, culinária, religião, entre outros, abordados de forma genérica, superficial, e carregada de equívocos. No ano 2000, iniciei um projeto de divulgação, na internet ${ }^{1}$, de fontes chinesas traduzidas para o português, que fossem de domínio público. As dificuldades foram imensas, devido à ausência quase absoluta no mercado de

1 Projeto Orientalismo, hoje disponível em www.orientalismo.blogspot.com O projeto abrange diversas páginas sobre história e culturas de China e Índia, incluindo manuais básicos e traduções de fontes. 
traduções e manuais básicos sobre a história e a literatura chinesas. Do mesmo modo, quando preparava meu projeto de Doutorado em 2002, ouvi de um respeitável acadêmico que o estudo da China não era 'nem pertinente, nem viável e nem relevante. É uma moda, e vai passar'. Cito essas dificuldades para mostrar que, num passado muito próximo, o Brasil estava absolutamente despreparado para lidar com a China em termos econômicos, políticos e culturais. Em 2008, num texto intitulado "A fracassada sinologia brasileira", praticamente constatei a repetição desse mesmo diagnóstico. Mesmo com a repercussão das olimpíadas de Beijing, o país carecia de pessoal qualificado para interpretar os dados provenientes do mundo chinês.

Desde então, algumas mudanças significativas foram feitas nesse quadro. A fundação do Instituto Confúcio no Brasil veio resolver a crônica carência de cursos de língua chinesa. ${ }^{3}$ Tal iniciativa pressupõe que possamos contar, daqui a alguns anos, com uma mudança daquele quadro pouco animador que citamos antes. Contudo, essa introdução foi necessária para que eu pudesse contextualizar a tradução que realizei do Sunæi bingfa 孫子兵法 em 2009 - aparentemente, a primeira a contar, no Brasil, com uma análise de fato do texto chinês. Esse ensaio trata de analisar as dificuldades e desdobramentos dessa empreitada, tendo em vista as limitações técnicas e culturais com as quais nossa sociedade ainda passava a menos de quatro anos atrás. Embora muita coisa tenha sido feita nesse tempo, é perturbador e preocupante a maneira com que tem sido tratada a questão da China no Brasil. A tradução do Sunz̧i bingfa 子孫子兵法 representa, talvez, um resumo de todo esse quadro complexo e difícil de lidar que tem sido o desenvolvimento de uma sinologia brasileira.

\section{$O$ contexto da tradução}

Quando fui convidado a realizar a tradução do Sunz̨i bingfa 孫子兵法, no ano de 2009 pela Jardim Editorial, inicialmente não fiquei muito entusiasmado. Já naquela época existiam, pelo menos, dez versões diferentes do livro em português. O Sunzi bingfa 孫子兵法, com certeza, o livro chinês mais divulgado no Brasil: contabilizei, para a realização desse texto, que já foram feitas quarenta e seis versões do livro, e mais vinte e sete análises do livro voltadas para assuntos administrativos ou de autoajuda. Visto assim, poder-se-ia argumentar que havia uma divulgação

2 Disponível em http://orientalismo.blogspot.com.br/2010/05/fracassada-sinologia-brasileira.html 3 Antes disso, a Universidade de São Paulo era a única no país a oferecer um curso de graduação em língua chinesa. 
razoável de textos chineses no país. Contudo, seria um grande equívoco. Se o Sunzi bingfa 孫子兵法 tinha ao menos dez versões em 2009, textos fundamentais como o Lunyu 論語 de Confúcio 孔夫子 ou o Daode jing 道德經de Laozi 老子 não contavam com mais de cinco versões cada. Notem que quando uso a palavra versões, busco indicar que se tratavam de traduções do inglês ou do francês, e não do chinês. Praticamente se desconheciam outros textos. Uma coletânea solitária de Lin Yutang 林語堂, Sabedoria de China éndia, publicada em 1957, reinava solitária como uma das poucas fontes de fragmentos sobre a literatura chinesa. A importancia de compreender, 1962, do mesmo autor, complementava esse quadro de ausências. Ignorava-se a produção feita em Macau - notadamente a do Padre Guerra, tradutor de Confúcio - ou mesmo, pela Edições em Línguas Estrangeiras.

O desinteresse pela literatura chinesa se dá, em grande parte, pelos problemas na educação brasileira. Até hoje, não há história asiática no ensino básico do país. China e Índia são pontualmente citados a partir da época das navegações portuguesas, para ressurgirem no contexto do imperialismo no século XIX, e acabou-se. Nas universidades, são pouquíssimos os grupos de estudos dedicados ao tema, posto que a história da Ásia é optativa, quando existe, e não obrigatória. Mesmo assim, esses grupos ainda sofrem com a visão obscurantista de parcelas da intelectualidade brasileira que, inspirada num modelo 'nacionalista', pretendem que o estudo de história antiga, medieval, e de outras civilizações 'estranhas' ao contexto brasileiro devem ser secundarizadas - ou mesmo, abandonadas. Assim sendo, o campo da história chinesa sempre esteve em aberto. Grande parte dos 'especialistas' em cultura chinesa que por aqui existiam eram figuras ligadas a dois campos bastante distintos: os praticantes de artes marciais, e o público ligado à administração de empresas.

O primeiro grupo fazia uma abordagem esotérica da cultura, misturando elementos da prática marcial com religião, filosofia e medicina 'orientais' (isto é, juntando as culturas chinesa, indiana, japonesa e coreana num mesmo todo). Se por um lado esse interesse era autêntico, por outro ele era desprovido de qualquer sistemática confiável, sendo contaminado pela absorção dogmática de versões superficiais e estereotipadas da história e literatura chinesa.

Já o segundo grupo, ligado à ciência da administração, não possuía qualquer preocupação maior com a questão da cultura chinesa em si. Seu interesse específico pelo Sunz̧i bingfa 孫子兵法 se deu pela importação de modelos empresariais europeus e americanos, que afirmavam se inspirar no livro para desenvolver suas estratégias de gestão. Foram esses dois grupos - tão diferentes entre si - que articularam, de um modo ou de outro, o interesse pelo Sunzi bingfa 孫子兵法. 
Isso fez com que,em 1983, surgisse a primeira versão do livro no Brasil. Para nossa surpresa, a versão publicada era a de James Clavell, autor de Xógum e Taipan, romances de inspiração orientalista com certa repercussão na época. Ainda assim, ela era inspirada na tradução de Lionel Giles, de 1910, constituindo uma leitura de segunda mão; e durante anos, foi a única tradução disponível no mercado brasileiro. Em torno da década de 1990, algumas outras versões surgiram, muitas de qualidade totalmente duvidosa. Era esse quadro, basicamente, que ainda se apresentava em 2009, quando me foi apresentada a oportunidade de realizar a tradução.

Meu interesse despontou a partir da leitura de algumas dessas versões. Duas delas foram feitas a partir de traduções inglesas de alta qualidade, e podemos considerá-las como boas. Todavia, o problema da tradução representa certos desafios e dificuldades, que se refletem na adaptação ao português. Do mesmo modo, percebi que não havia uma preocupação histórica com o texto, mas sim, a insistência constante em tratá-lo como um simples livro de autoajuda ou de administração de empresas. Diante de uma série de versões problemáticas e incompletas, constatei que a realização desse trabalho poderia criar uma perspectiva diferente sobre a obra. Essas preocupações me levaram, pois, a encarar o desafio de realizar a tradução do texto para o português.

\section{Dificuldades na tradução}

Obviamente, a tarefa de traduzir o Sunzৃi bingfa 孫子兵法 seria facilitada pela existência de boas traduções em outras línguas, com as quais eu poderia recorrer caso fosse necessário. No entanto, esse recurso também se mostrou problemático. As opções feitas pelos autores ingleses ou franceses envolviam especificidades de suas línguas, ou mesmo de estilo, que não seriam adequadas ao português. Além disso, o texto chinês em si merece um olhar próprio, cuja tradução cotejada facilmente destorce.

Um dos exemplos mais significativos foi, a começar, pelo próprio título. Optei por utilizar 'Lei da Guerra' por entender que 'Arte' era um termo bem distante

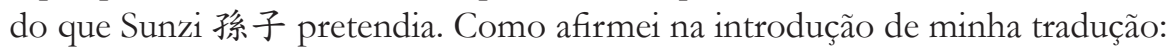

Sunzi 孫子 está praticamente dando ordens, ou recomendações para serem seguidas à risca, não são conselhos para meditar. Eles devem ser empregados para fazer planos pragmáticos, nos quais vidas estão em jogo. Eis a razão pela qual, como citei logo no início, optei por traduzir "Fa法” por "Lei”, e não "Arte". O que há, aqui, é um método, tecnicamente raciocinado após uma observação profunda sobre a realidade das operações de combate. Tal experiência é categórica e afirmativa. (2010, p. 12) 
O termo 'Arte' transformara-se num hábito desde a tradução do Padre Amiot, feita em 1772. Amiot buscava comparar a obra chinesa com a Arte da Guerra de Maquiavel (1520), e criou uma 'moda', entre as traduções, que se perpetuou. Todas as versões do livro, no Brasil (incluso a minha, mas veremos a razão adiante), empregam o título de Arte da Guerra. Assim, busquei deixar claro na introdução que não concordava com esse título, tanto quanto pretendia uma outra estrutura do texto.

A Lei da Guerra de Sunæi, a meu ver, é um texto para ser traduzido no modo verbal imperativo. Ele apresenta comandos a serem seguidos, e não um manual de

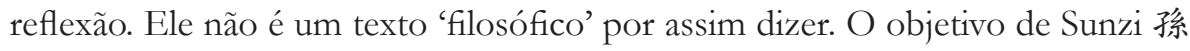
子 era evitar a guerra; e se não pudesse evitá-la, então vencê-la a qualquer custo, com o mínimo de perdas. Por isso, o texto é simples, conciso e direto. Arriscava, com isso, fazer um texto 'chato' para o leitor brasileiro, acostumado a versões romanceadas do livro. Essa é uma dificuldade perene na tradução dos clássicos no Brasil. Pretende-se que os livros antigos devem ser todos traduzidos num linguajar 'bíblico', baseado no português do século 19. Esse hábito implica num problema curioso: o leitor tende a acreditar que a 'simplificação' da linguagem significa uma 'menor erudição' do tradutor/autor. Novamente, porém, optei por utilizar um linguajar que, de certa forma, recuperasse a intenção de Sunzi 孫子 de criar um manual militar. O uso de uma linguagem simples não implica na perda do texto; se evitarmos banalizações ou vulgaridades, o texto torna-se acessível sem, contudo, ser indevidamente 'atualizado'.

Do mesmo modo, algumas palavras no texto chinês merecem atenção especial. No capítulo 5, a palavra “弩 $n u^{\prime}$ ”, por exemplo, designa a balestra ('crossbow') utilizada na guerra. Pode parecer um detalhe simples, mas é bastante significativo: como essa arma só surgiu em torno do século $\mathrm{IV}^{4}$, isso implica dizer

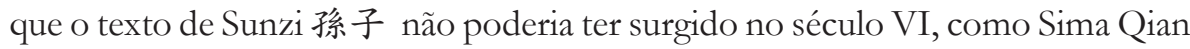
司馬遷 afirmava (SUNZI, 2010, p. 14). Ao menos, isso significaria que a versão de que se dispunha na dinastia Han 漢朝 era do século IV, o que impossibilitaria localizar a vida de Sunzi 孫子 em período anterior com precisão. É um detalhe pequeno, mas historicamente importante. Em outras versões, porém, a tradução equivocada - até mesmo do inglês - induz a erros grosseiros. Numa delas, por exemplo, a palavra 'Tian' 天 (Céu, Tempo, Clima) é traduzida como 'Paraíso', numa interpretação errônea e deslocada da palavra inglesa 'Heaven'. ${ }^{5}$ Isso mostra

\footnotetext{
4 Como convenção, utilizaremos o sinal '-‘ no lugar de 'a.C.', como é de uso por alguns sinólogos.

5 Optei por utilizar a palavra Tempo, com todas as conotações que ela implica: condições temporais, clima, Céu, estações, etc. A escolha se deu em função do que, no meu entendimento, significa ‘Tian’ dentro do contexto: a observação das regras da natureza, da conformação do clima, do momento da ação.
} 
que o revisor do português estava bastante desatento, e desconhecia o sentido do conceito em chinês.

\section{Dificuldades na adaptação}

Essas questões internas ao texto são uma atribuição do tradutor, e implicam nas opções que ele fará. Por causa disso, o processo da tradução inevitavelmente necessita de algum conhecimento da língua e da cultura em questão. Todavia, outras dificuldades, específicas do contexto brasileiro, se interpõem na tradução do chinês. Como vimos, a ausência de conhecimento sobre da China dificulta, sobremaneira, o entendimento dos textos e formas de expressão dessa civilização. Assim, certos recursos foram sendo utilizados, no desenvolvimento do livro, que denotam a caracterização desses problemas.

Uma delas foi - novamente - a tradução do título. Como indiquei anteriormente, entendo que a tradução ideal do título seria 'Lei da Guerra'. Após a venda dos direitos, os responsáveis pela editoração informaram-me que o livro manteria, na capa, o título de 'Arte da Guerra' de 'Sun tzu'. Acreditava-se que, se o livro fosse lançado como 'Lei da Guerra de Sunzi', ele não seria identificado pelos leitores como sendo o mesmo. Ou seja, as formas 'Arte da Guerra' e 'Sun tzu' ficaram tão cristalizadas, no imaginário brasileiro sobre o livro, que a opção por mantê-los parecia coerente. De fato, essa perspectiva acabou se mostrando acertada, e o livro foi bem recebido pelo público, tendo sucessivas tiragens.

Alguns pontos em particular, porém, foram objeto de minha atenção e discordância em relação ao projeto editorial. Na capa, é utilizada uma Katana (espada japonesa) como símbolo da guerra, junto com o uso aleatório do ideograma Zhi 知 (sabedoria prática, conhecimento). No interior, o nome 'Sunzi' é inexplicavelmente 'vertido' para o alfabeto japonês Katakana (スソシ, 'susoshi'). Diante de minhas indagações sobre essas questões, fui informado que esse era o projeto visual vigente, e que seria mantido porque havia ficado esteticamente atraente. Por fim, na parte final da versão em capa dura do livro, uma seção para anotações foi colocada, com o seguinte texto introdutório:

'Anotações do leitor: a Arte da Guerra é uma das ferramentas mais valiosas para o crescimento pessoal e profissional nos dias atuais. Comece a planejar suas metas e objetivos baseados nos mandamentos e estratégias fundamentais para alcançar o sucesso'. ${ }^{6}$

6 Esse texto, obviamente, não é de minha autoria. 
Notem que todo o conjunto de estereótipos anteriormente citados foi resumido nesse pequeno fragmento. A 'Arte da Guerra' (contrariando a transliteração que apresentei ao longo do texto) serviria para alcançar sucesso profissional e pessoal, reproduzindo a velha tendência de fazer com o que o livro, na verdade, se adequasse ao público que o lê.

Ao realizar a tradução do Sunæi bingfa 孫子兵法, pretendi que o livro fosse capaz de atender a um público interessado na cultura chinesa, de um modo mais amplo, sem restringir sua abordagem ao aspecto marcial ou empresarial. Apesar de saber que esse não seria nem o momento e nem o espaço para o desenvolvimento de uma tradução 'erudita' (isto é, acadêmica), meu objetivo era contemplar um interesse relativamente diferenciado dos clássicos chineses. Por essa razão, inclui na introdução uma parte sobre a escola dos estrategistas chineses, de modo a despertar a atenção do público para os vários outros clássicos militares que existem na literatura chinesa.

\section{Desdobramentos}

Contudo, após quarenta e seis versões, o Sunzi bingfa 孫子兵法 continua sem uma versão acadêmica. Do mesmo modo, outros clássicos militares chineses seguem praticamente desconhecidos no âmbito brasileiro, apesar do sucesso massificado do livro 7 . A recepção positiva do livro - e a ausência de críticas ao texto ou mesmo, aos detalhes anacrônicos do projeto editorial - demonstram que o público brasileiro segue desconhecendo elementos cruciais do pensamento e da cultura chinesa. Embora já se sinta um aumento gradual de manifestações no sentido de 'saber mais' sobre a China (aliadas à vinda de um grande contingente de chineses para o Brasil), não há nenhuma proposta sistemática organizada no sentido de levar esse debate aos centros acadêmicos e universitários. O panorama intelectual brasileiro depende em grande parte, ainda, de iniciativas individuais e isoladas, com sérios problemas de continuidade.

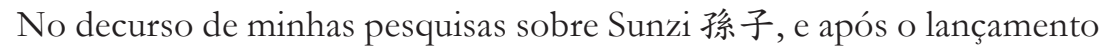
do livro, acabei convidado a escrever um livro sobre a história da estratégia na China (que seria chamado de 'A Arte da Guerra Chinesa'). A proposta do livro seria de apresentar os diversos autores que compuseram a Escola dos estrategistas, desde Taigong até Mao Zedong (Mao Tse-tung), construindo um panorama histórico sobre a questão na história chinesa. O livro criaria também uma abertura

7 Apenas uma tradução desses clássicos foi feita no Brasil pelo monge Marcos Beltrão, e está disponível em http://www.marcosbeltrao.com/mestres_de_guerra.php 
para a futura tradução de outros clássicos estratégicos. Por mais paradoxal que possa parecer, a boa venda do Sunzi bingfa 孫子兵法 desmotivou o investimento em novos projetos nesse sentido. A lógica imediatista do capitalismo brasileiro é notável. Todavia, finalizei o projeto e o publiquei na rede, deixando-o disponível ao público. ${ }^{8}$

Por outro lado, um dos destaques dados a minha tradução foi de origem, no mínimo, curiosa. Dois dos mais temidos traficantes do Rio de Janeiro, Sandro Amorim (o 'Peixe') e Antônio Lopes (o 'Nem') foram presos em novembro de 2011. Em um de seus esconderijos, o único livro disponível era, justamente, a tradução que havia feito da Lei da Guerra. ${ }^{9}$ Isso revigorou o interesse pela obra, aumentando subitamente o número das vendas, segundo informe da própria editora. Podemos, aqui, propor várias interpretações para esse acontecimento: uma delas é de que o acesso ao texto, já vulgarizado, poderia estar atingindo camadas sociais variadas. Por outro lado, fica claro que o novo surto de curiosidade pela obra se devia aos efeitos midiáticos de sua apreensão, no contexto criminal - e, portanto, não pelo valor da obra em si. Será, pois, que os brasileiros dependem, inequivocamente, de modismos para dirigirem seus interesses literários?

Contudo, não devemos menosprezar o potencial representado pela obra de Sunzi para despertar, gradualmente, a atenção brasileira para um conhecimento sinológico legítimo. Recentes traduções da Lei da Guerra de Sunbin 孫臏兵法 ou mesmo do Livro das Trinta e Seis Estratégias 三十六計 demonstram que, lentamente, é possível construir algo mais, a partir de interesses derivados do Sunz̧i bingfa 孫子兵法. Devemos ressaltar: são traduções derivadas do inglês ou francês, e feitas para nichos específicos do mercado. Ainda assim, porém, representam um aumento das leituras disponíveis, o que é sempre bem vindo.

\section{Conclusão}

As dificuldades que apresentei, neste ensaio, visam demonstrar o imenso despreparo da sociedade brasileira em compreender o desafio que a cultura chinesa representa na modernidade. Para além do imediatismo nos negócios econômicos e políticos, o diálogo com a China depende de uma capacidade de compreensão

8 Ver em: http://estrategiaschinesas.blogspot.com

9 A reportagem, com fotos, pode ser conferida nesse link: http:// noticias.uol.com.br/cotidiano/ultimas-noticias/2011/11/13/policia-encontra-aquario-e-livro-a-arte-da-guerra-em-luxuoso-casarao-na-rocinha. htm 
mútua, que está para além do simples domínio útil das línguas. ${ }^{10}$ Nenhuma civilização pode ser entendida sem o estudo de suas raízes; no entanto, o panorama cultural do Brasil sofre, ainda, de um interesse meramente superficial pelo que não é euro-americano. O que apresento aqui, pois, é antes de tudo uma constatação. As dificuldades técnicas de uma tradução podem ser, de certo modo, resolvidas (ou assumidas) pelo tradutor no âmbito de seu desenvolvimento; todavia, as questões culturais que envolvem sua recepção e consumo apresentam desafios que dificilmente podem ser superados pela simples beleza e profundidade da tradução. No caso brasileiro, o aumento de traduções chinês-português nos últimos dois anos permite supor o despertar do interesse pela China; mas há que se ter cuidado em não escolher obras que meramente repitam ou aprofundem estereótipos sobre essa civilização. A tradução de outros clássicos chineses se reverteria, a meu ver, numa contribuição fundamental para a formação de especialistas em China no Brasil. Isso consolidaria um conhecimento aprofundado da civilização chinesa, e melhoraria sobremaneira a capacitação dos sinólogos envolvidos nos mais diversos níveis de atuação dentro do país, fosse à economia, educação, política e ciências. Porém, é possível mais do que isso: o estudo da civilização chinesa, e de suas formas de pensar, contribuiria na discussão de nossos próprios saberes, apresentando-lhes uma faceta inédita do mundo, e quebrando seu logocentrismo reincidente. Aprender a China nos possibilitaria repensar a nós mesmos, num sentido enriquecedor, criativo e inovador, próprio de uma cultura multifacetada como a brasileira.

Afinal, como dizia o próprio Sunzi: 'tudo é questão de preparação'.

\section{Referências}

SUNZI. A Arte da Guerra, tradução de André Bueno. São Paulo: Jardim dos Livros, 2010.

BUENO, André. "A Arte da Guerra Chinesa - a história da estratégia na China, de Sunzi a Mao Zedong”, 2011. Página Eletrônica: www.estrategiaschinesas.com

LEVI, Jean. Os 36 estratagemas: manual secreto da arte da guerra. São Paulo: Ciranda cultural, 2007.

LIN, Yutang. Sabedoria de China e Índia, tradução de Ary de Mesquita e outros. Rio de Janeiro: Pongetti, 1957.

10 Um excelente texto sobre as questões éticas que envolvem a tradução é de OLIVEIRA, Maria Clara Ética ou Éticas da tradução? In "Os Limites da Tradução", no IV CIATI - Congresso Ibero-Americano de Tradução e Interpretação. São Paulo: Centro Universitário Ibero-Americano - UNIBERO, Maio de 2007. 
LIN, Yutang. A importância de compreender, tradução de Mário Quintana. Porto Alegre: Globo, 1962.

SAWYER, Ralph. A arte da guerra: Sun tæu e Sun pin. São Paulo: Martins Fontes, 2002. 